\title{
ALIENAÇÃO E SEPARAÇÃO: ELEMENTOS PARA DISCUSSÃO DE UM CASO CLÍNICO
}

\author{
Maria Angélica Mello Pisetta* \\ Vera Lopes Besset ${ }^{\#}$
}

\begin{abstract}
RESUMO. Este artigo discute a causação do sujeito a partir dos conceitos de "alienação" e "separação" na perspectiva lacaniana, valendo-se da análise de um caso clínico da literatura psicanalítica recente. Delimita-se, no artigo, o tema das escolhas de um sujeito a partir das determinações significantes do Outro, considerando-se a alienação como a primeira e mais originária operação que socorre o ser humano, servindo-lhe de matriz. Em seguida, destaca-se a separação como um momento lógico em que o sujeito vem produzir algo de particular através dos significantes advindos desse mesmo Outro. Dados de um caso clínico em que a direção do tratamento pôde evidenciar de forma paradigmática esses dois momentos lógicos conferem relevo clínico à discussão.
\end{abstract}

Palavras-chave: Alienação, separação, sujeito.

\section{ALIENATION AND PARTITION: ELEMENTS FOR DISCUSSION OF A CLINICAL CASE}

\begin{abstract}
In this paper we will discuss the subject's causation from the concepts of "alienation" and "partition" in a Lacanian perspective, drawing upon the analysis of a clinical case of the recent psychoanalytic literature. It is delimited, in the article, the theme of someone choices from the Other significant determinations, considering "alienation" as the former and the most original operation that rescues the human being, serving him as a matrix. Then, we emphasize "partition" as a logical moment in which the subject produces something particular through the significant that comes from this same other. Some data of a clinical case, where the treatment direction presented, in a paradigmatic way, these two logical moments, give clinical highlight to our discussion.
\end{abstract}

Key words: Alienation, partition, subject.

\section{ALIENACIÓN Y SEPARACIÓN: ELEMENTOS PARA DISCUSIÓN DE UN CASO CLÍNICO}

RESUMEN. Este artículo trata del tema del sujeto a partir de los conceptos de "alienación" y "separación" en la perspectiva Lacaniana, basándose en el análisis de un caso clínico de la literatura psicoanalítica reciente. Está delimitado, en el artículo el tema de las elecciones de un sujeto teniendo en cuenta la alienación como la primera y la originaria que rescata al ser humano, que sirven de cuño. Entonces, hay una lógica separada como un momento en que el sujeto tiene que producir algo especial encontrándose con los significantes de ese Otro. Los datos de un caso clínico caso, en que el seguimiento del tratamiento pone de manifiesto pruebas que la paradigmática confiere esos dos momentos lógicos, proporcionará alivio a la discusión clínica.

Palabras-clave: Alienación, separación, sujetos.

Doutorado em Psicologia pela Universidade Federal do Rio de Janeiro, Brasil(2006). Professora assistente de ensino da Universidade Católica de Petrópolis, Brasil.

\# Doctorat 3ème cycle pelo Université Paris-Descartes, França(1983). Professora Adjunta IV da Universidade Federal do Rio de Janeiro , Brasil. 


\section{ALIENAÇÃO E CAUSAÇÃO DO SUJEITO}

As questões referentes à causação do sujeito sempre ocuparam a psicanálise. A possibilidade de se pensar e teorizar sobre a causa efetiva de um sujeito exige, como “(...) um rechaço da clássica ideia segundo a qual um sujeito é causa sui, ou seja, causa de si mesmo" (Harari, 1990, p. 220). Para discutir estas ideias, partiremos dos conceitos de alienação e separação adotados na lógica por Lacan (1988a) em um momento de virada teórica de seu ensino. A partir disso, abordaremos a direção de um tratamento tendo em vista esses dois operadores lógicos, valendo-nos de dados extraídos de um caso clínico recentemente publicado por Fuentes (2008).

Laurent (1997) destaca que a apresentação destas duas operações, feita em 1964, demonstra uma ruptura e uma nova aliança na obra de Lacan. A ruptura se deve ao fato de que as influências linguísticoestruturalistas (oriundas da obra de Saussure, especialmente) que sustentaram suas definições do funcionamento do inconsciente com base na metáfora e na metonímia começam a ficar para trás. A aliança que Lacan passa a estabelecer, através desses conceitos, é com a lógica formal, na busca de melhor conceituar o que da linguagem faz barreira à comunicação e não pode ser metaforizado.

É no limite estrutural da própria linguagem que a lógica socorre o pensamento lacaniano e as notações algébricas passam a ter seu lugar. Esse remodelamento da teoria principal sobre a linguagem, embora iniciada desde os primórdios de seu pensamento, pode ser demarcada no estabelecimento do conceito de objeto $a$, em 1962-63. O uso da notação $a$ " “...) visa eliminar a metáfora" (Brousse, 2008, p. 67). Nesse sentido, as operações de constituição do sujeito passam também a ser consideradas a partir desta perspectiva, que revê a intenção inicial da submissão ao Outro da linguagem. Para Milner (2010), a mudança na própria linguística está na base das reformulações da teoria lacaniana: "No dispositivo posto em prática a partir do 'Discurso de Roma', a posição da linguística é clara: ela permite e justifica uma nova teoria do Um e da causalidade" (Milner, 2010, pp. 187-188).

É importante lembrar que as duas operações discutem o cogito cartesiano, que consiste em reconhecer a existência do homem onde há pensamento. A máxima cartesiana, que inaugura o pensamento moderno, reconhece que o homem é porque pensa, em que pese ao registro da consciência nesta articulação. A proposição de Freud (1915/2006) sobre o conceito de inconsciente amplia esta articulação, por compreender que o homem também existe no inconsciente, lá onde ele, aparentemente, não pensa. Neste sentido, a referência de Lacan ao sujeito cartesiano destaca e reafirma este antecedente da psicanálise freudiana, pois, fundamentalmente (e inauguralmente), em Descartes (1996) o sujeito é pensado como aquele que é, enquanto pensa:

Eu sou, eu existo; isso é certo; mas por quanto tempo? A saber, por todo o tempo em que eu penso; pois poderia talvez ocorrer que, se eu deixasse de pensar, eu deixaria ao mesmo tempo de ser ou de existir. Nada admito agora que não seja necessariamente verdadeiro: nada sou, pois, falando precisamente, senão uma coisa que pensa (Descartes, 1996, p. 269).

A perspectiva lacaniana amplia as bases do sujeito cartesiano, e ainda destaca, pelo conceito de inconsciente, o assujeitamento a esse pensar. Deste modo, entendemos que Lacan redimensiona Freud e Descartes quando propõe, no início de seu ensino, que o inconsciente é estruturado como uma linguagem (Lacan, 2008), aplicando os efeitos de linguagem ao inconsciente freudiano. Desta maneira, formalizar a estruturação do sujeito do inconsciente, agora a partir da lógica (1964), recoloca em questão as relações entre o saber e o sujeito, a partir do Outro.

Com estas novas concepções, Lacan também revê a teoria econômica de Freud (decorrente da mecânica do século XIX), que não dispunha dos instrumentos da lógica formal do século XX. Laurent (1997) ressalta que a utilização da lógica por Lacan inclui o fator tempo, fundamental para falarmos da transferência, nessa nova perspectiva. $\mathrm{O}$ autor sublinha que, segundo Lacan, "(...) uma função temporal pode ser introduzida dentro da "logicização" das operações que constituem o sujeito" (Laurent, 1997, p. 31). O conceito de retorno, citado no título de uma das lições desse importante seminário, intitulada $O$ campo do Outro e o retorno sobre a transferência (1988a), testemunha esta tentativa de situar o fator tempo na constituição do sujeito, bem como na transferência. A esse respeito, também podemos pensar com Miller (2010) sobre o acento lacaniano da transferência em sua relação com o objeto $a$, para além da suposição do saber.

A utilização dos conceitos da lógica formal, especialmente dos vels de alienação e separação, é pensada a partir da teoria dos conjuntos, com a proposição de outras possibilidades de apresentação do conector $o u$, para destacar as operações pelas quais verificamos as conjunções-disjunções na relação do sujeito com o Outro (Doumit, 1996; Lacan, 1988a). 
Harari esclarece que a utilização do vel (ou, em latim) visa ressaltar uma disjunção que, classicamente, na matemática, é dividida em inclusiva e exclusiva. $\mathrm{O}$ que Lacan promove é a proposição de um novo tipo de vel, ou de uma nova forma de pensar o ou, para indicar as relações constitutivas entre o Outro da linguagem e um sujeito. Para Lacan, por ela, “(...) este vel indica uma relação eletiva bastante paradoxal: traz como consequência um "nem um nem outro", seja qual for a opção abraçada" (Lacan, 1988a, p. 243). Sublinhamos que a condição para a causação de um sujeito é uma falta radical a cada um dos conjuntos. Como podemos constatar, a utilização que Lacan faz da lógica obedece a um rigor conceitual, descartando a forma habitual de pensar as conjunções e disjunções entre conjuntos.

Que escolhas tem o sujeito, já que se constitui a partir do Outro ${ }^{1}$ ? É a questão que parece guiar Lacan nesse ponto. $\mathrm{O}$ que definiria seu ser, o que garantiria sua existência, se suas referências iniciais (significantes) são trazidas pelo Outro? Em outros termos, como pode o sujeito se definir se as definições trazem a marca do Outro?

A operação da alienação é a primeira a ser apresentada por Lacan, que destaca que ela é "(...) a primeira operação essencial em que se funda o sujeito" (Lacan, 1988a, p. 199). Operação referida à origem, ou a uma fantasia das origens, encontra uma relação íntima com a identificação. Laurent chega a dizer que "a alienação é o fato de que o sujeito, não tendo identidade, tenha de identificar-se a algo" (Laurent, 1997, p. 43). É pela falta radical de identidade que a operação da alienação se constrói. Pergunta-se, então: de que falta se trata? Para Laurent, tal falta pode ser representada a partir do efeito da linguagem sobre o sujeito e se relaciona com o fato de que "(...) o sujeito não pode ser inteiramente representado no Outro, sempre há um resto" (Laurent, 1997, p. 37).

O vel da alienação revela um sujeito que, no mesmo momento em que é representado pelo significante, não pode obter sua essência a partir desta representação. Contudo, há uma promessa de ser, concedida pelos significantes primordiais advindos do

1 Obviamente, a referência ao campo do Outro aqui situa a escolha do sujeito no que se refere ao inconsciente. Não nos referimos, deste modo, a qualquer sorte de escolha consciente. É nesse sentido que entendemos a citação de Harari (1990): "Quando de algum modo o sentido se realiza em um sujeito em virtude da ação do Outro, deixa caído no caminho uma região de sem sentido. Essa região é, justamente, a daquilo que é inconsciente" (Harari, 1990, p. 241).
Outro. Eis o que afirma, recentemente, Nascimento (2010), sobre esse tema:

Para que haja alienação, não basta que o significante venha do Outro (...). "É a articulação produtora de sentido que gera a alienação, o sujeito sendo capturado na armadilha e apagado no processo de representação que teve lugar no campo do Outro" (Nascimento, 2010, p. 286).

Para alienar-se, o sujeito tenta assumir suas identificações primárias; porém sua definição a partir do significante promove uma vacilação em seu ser, já que parte do Outro sua designação e, ainda assim, isso é tão somente uma fantasia. Ainda que o sujeito se agarre às identificações primárias, provindas do Outro, o que ele encontra é apenas seu desvanecimento Lacan (1988a), já que não há coincidência absoluta entre o Outro e o sujeito. Essas questões, fundamentais para a psicanálise, são também cruciais na clínica, lugar por excelência do questionamento sobre o desejo e as escolhas do sujeito.

\section{ALIENAÇÃO E CLÍNICA}

Entendemos que Lacan (1988a) utiliza a lógica para marcar, com a alienação, a impossibilidade de o sujeito se constituir apartado do Outro, do campo do sentido. Por outro lado, o sujeito também não pode surgir inteiramente do campo do Outro, porque isso implicaria em uma identificação primária totalitária, que diria o que é o sujeito, numa letalização de seu ser.

Assim, entendemos a esquematização aqui proposta por Lacan a partir da concepção de que pela alienação o sujeito se encontra dividido entre o ser e o sentido, situando-se nessa divisão, nessa fenda. Em assim sendo, o sentido não comporta toda a existência do sujeito, tampouco a existência se encontra totalmente definida pelo sentido. Esta advertência remodela também o lugar do analista e os limites do sentido na condução do tratamento. Lacan (1988a) situa o ser do sujeito sob o sentido, submetido ao campo do Outro. Por esta divisão constitutiva, a referência ao Outro da linguagem responde por uma parte da gênese do sujeito.

Por outro lado, como acentua Brodsky (2008), valorizando a noção de objeto, é necessário inicialmente identificarmos o efeito imaginário da alienação, pelo qual o sujeito se vê a partir da exclusão de um outro qualquer, na constituição do eu. Aí verificamos uma exclusão necessária, ainda que 
imaginária, que inaugura a relação dual com o outro. Não obstante, esta é uma primeira abordagem da operação lógica da alienação, estruturada, por sua vez, numa alienação simbólica constitutiva. A ênfase simbólica conferida às operações de alienação e separação justifica o uso da lógica como uma tentativa de minimizar os efeitos imaginários destas operações. Se no nível imaginário a tônica da alienação é a rivalidade, sua fundamentação lógica exige que consideremos uma dependência significante radical do sujeito para com o Outro.

Neste ponto, retomamos a leitura freudiana presente em Mal-estar na civilização (1930/1986), onde o autor destaca que não se pode conceber nenhuma outra necessidade tão imperiosa na infância quanto a da proteção de um pai. Obviamente, a leitura lacaniana desta paternidade se desloca para o campo da linguagem e toma o significante como sua representação. Nestes termos, o nascimento do sujeito é garantido somente a partir da linguagem.

Como se trata de uma proposição lógica, baseada na teoria dos conjuntos, Lacan (1988a) esclarece que o vel da alienação é uma perspectiva de modificação da operação da união. A união, como operação lógica clássica, propõe a não exclusão de um termo na escolha de qualquer outro. Assim, não podemos pensá-la como uma escolha de fato, já que se pode escolher um termo ou o outro, ou ainda um termo $e$ o outro. A proposição de Lacan altera esta modalidade, pois indica que na escolha pelo sentido não há manutenção dos dois termos, tampouco de um em sua magnitude. Assim algo se perde, já que toda escolha aqui implica em uma perda intrínseca. É nessa fenda que o sujeito se estrutura; ou seja, entendemos que, embora seja um tipo de reunião lógica, na alienação ocorre uma subtração de algo do sujeito e do Outro.

Outro modo de pensar na modificação que Lacan opera em torno da lógica clássica é considerar que, como é uma união, ainda que modificada pela proposição lacaniana, a alienação define-se por aquilo que pertence aos dois conjuntos aqui chamados ser e sentido. Assim, pela lógica, dois elementos que estão em dois conjuntos distintos, pela união, são contados apenas uma única vez. Esta lógica é aplicada à causação do sujeito. Lacan refere-se a dois conjuntos, como já frisamos: o do ser (ôntico) e o do campo do sentido (linguagem). $\mathrm{O}$ elemento que pertence a ambos e é contado apenas uma vez é o não senso (Lacan, 1988a). É o não-senso que se encontra presente no sentido, pela ambiguidade significante que revela uma falta radical de sentido e que também se presentifica no campo do ser, já que não há significante que diga o que é o sujeito.
Podemos formulá-lo ainda de outro modo: a proposição deste vel inscreve-se para o sujeito a partir da oposição entre o ser e o sentido (campo da linguagem). Como a escolha possível é sempre desfalcada, o que se encontra é sempre uma perda, que se faz notar pela divisão que constitui o sujeito. Se em alguma parte ele se identifica com um significante (um sentido sobre sua existência), por outro lado ele se situa numa afânise (num desaparecimento desse sentido). Assim a definição de seu ser encontra-se sempre parcial, inconsistente.

Isso representa uma subversão do cogito cartesiano (penso, logo sou), já que não há coincidência entre pensar e ser. A articulação freudiana que fundamenta o conceito de inconsciente (ou seja, onde não penso, sou) já havia subvertido esta máxima. Com a lógica, Lacan formaliza esta perspectiva e, a partir disso, a linguagem, como matriz constitutiva do sujeito, é também submetida à lógica, substituindo o "pensar" cartesiano.

É no intervalo que se constitui pela união destes dois campos que Lacan situa o S1, o significante inaugural ao qual o sujeito está referido. Note-se que o S1 (significante primordial) em si não significa nada, resguardando este núcleo de não senso. Como sentido, ele é apenas letra, resguardando o sem sentido, e como ser, ele é necessariamente referido ao significante.

Como vemos, ser e sentido aparecem aqui excluindo-se mutuamente, como possibilidades de escolha; porém, como nos diz Lacan (1988a), não há, em rigor, uma escolha, mas uma escolha condicionada por uma perda. Se escolhermos o ser, ele vem amputado de uma parte de não ser, marcado por um sem sentido; se optamos pelo sentido, ele é que se mantém amputado de uma parte de não sentido, não senso, presente do lado do ser. Como entendemos, é como se qualquer uma das escolhas testemunhasse uma impossibilidade, pois traz consigo uma parte da outra escolha, onde o sujeito se situa. A escolha se dá assim, sempre no encontro destas duas esferas. Se pensarmos que escolha tem o sujeito em sua constituição, veremos que a proposição lacaniana, através da lógica, sublinha que só há escolha forçada, pois o sujeito não tem como não perder algo, quando sua identificação inicial porta algo de não senso constitutivo.

É com o conhecido exemplo Ou a bolsa ou a vida (Lacan, 1988a) que Lacan formaliza sua definição de alienação. No seio desta aparente encruzilhada qualquer escolha (a da bolsa implica na perda das duas, e a da vida implica na escolha de uma vida, sem a bolsa) resulta em perda, não apenas na perda do que não se escolheu, mas numa perda intrínseca à escolha 
efetuada. Esta proposição implica o surgimento de um terceiro termo, o do conjunto vazio, "(...) com o que o sujeito se reencontra quando se recusa a entregar a bolsa" (Doumit, 1996, p. 23). Este conjunto vazio é o cerne de seu ser, indefinido no que tange ao sentido. Esta escolha condicionada é instaurada pela perda primordial, que se dá em virtude de o significante não poder dizer tudo o que é o sujeito.

Soler (1997) advoga que, a partir das conceituações da alienação e da separação, Lacan dá mais consistência à sua definição prévia do inconsciente estruturado como uma linguagem. Deste modo, para a autora, Lacan evidencia como esse inconsciente se estrutura tal como uma linguagem nas relações do sujeito com o Outro, ainda que o sem sentido radical seja constitutivo desta estruturação.

Outro ponto marcado por Soler (1997) é a consideração de que a abordagem lógica de Lacan é também, e essencialmente, uma abordagem clínica, pois é aí que os sujeitos estão às voltas com o Outro, procurando uma resposta sobre seu ser. Pela escolha alienante do sentido, o sujeito tem duas alternativas (vel da escolha forçada): ou petrifica-se num significante, identificando-se a ele, ou desliza interminavelmente entre os significantes, o que implica uma perda bastante marcada em qualquer uma das alternativas. $\mathrm{Na}$ petrificação temos a impossibilidade de o sujeito situar-se um pouco além do sentido imediato, na ausência de autoquestionamentos acerca de suas determinações. A vida é possível, e até a ação, mas sem singularidade.

A escolha pelo sentido, que implica um deslizamento na cadeia, é a escolha do analisando pela qual ele paga com um questionamento incessante. Nesse sentido, também se evidencia a ambiguidade da escolha forçada, já que uma escolha pelo sentido (deslizamento na cadeia) implica uma incidência maior do não senso. O caminho do sujeito do significante, como assinala Soler (1997), é vagar pela indefinição ou identificar-se a um significante, à custa de um desaparecimento. Há aí um impasse que, pela transferência, ressurge na análise. É nessa perspectiva que concordamos com Harari (1990), quando advoga que a análise se inicia a partir da separação.

\section{SEPARAÇÃO NA RELAÇÃO DO SUJEITO COM O OUTRO.}

Em se tratando da separação, operação final da causação do sujeito, é necessário situarmos uma torção na relação do sujeito com o Outro, sendo que aquilo que falta ao Outro também falta ao sujeito (interseção ou produto do efeito de linguagem). Neste sentido, a operação da separação se situa no produto dos dois conjuntos, na falta que acomete a ambos (Lacan, 1988a).

Com Lacan, vemos que a separação, pensada no registro da análise, evoca uma liberdade, mas à custa de um querer pronunciado no ato da análise. Assim, "a separação supõe uma vontade de sair, uma vontade de saber o que se é para além daquilo que o Outro possa dizer, para além daquilo inscrito no Outro" (Soler, 1997, p. 65); porém a condição para esta separação já se encontra presente no Outro, em seu desejo. Soler ressalta que temos que supor logicamente uma falta no Outro, para situarmos a separação. Em virtude desta falta no Outro não se pode falar do mesmo Outro na alienação e na separação.

$\mathrm{Na}$ alienação temos um Outro completo, infinito, portador dos significantes, enquanto na separação a condição lógica introduz um Outro faltante. Doumit (1996) destaca que o sujeito só se lança na alienação em virtude de uma promessa de ser, que se encontra na separação. Essa promessa só pode se cumprir tendo-se em vista uma falta no Outro, que é possibilitada pelo vazio constitutivo do sujeito.

O Outro barrado revela, por sua vez, a perda do objeto, fundamental para situarmos o lugar do analista. Esta falta é pensada por Lacan como objeto $a$, e ocupa, na lógica dos conjuntos, o que é faltante nos dois campos (o campo do sujeito e o campo do Outro). A impossibilidade de se dizer tudo o que se quer testemunha esta falta, comum aos dois campos (Lacan, 1988a). É na referência a uma falta radical de sentido que o objeto $a$ é situado no registro do real, indicando conceitualmente a radicalidade desta falta.

Outrossim, só a falta (tornada objeto pela operação da separação) faz o sujeito buscar que na linguagem continue a residir a impossibilidade de tudo dizer. Quando falamos da falta e do desejo do Outro, é da falta e do desejo do sujeito que tratamos. Uma psicanálise se baliza, deste modo, por uma busca de respostas que, por sua vez, produzam um saber sobre esta falta, incluindo o não senso. Como nos indica Laurent (1997), "Se admitirem que aquele elemento é fundamentalmente faltoso - que todos tem de definir suas posições com referência àquele símbolo - então tem a chance de alcançar o que conhece como valores da verdade em análise, isto é, valores de desejo" (Laurent, 1997, p. 35).

Lacan (1988a) situa a separação como um retorno, para o sujeito, da alienação constitutiva. Por este retorno, a falta do Outro é colocada à mostra, anunciada no para além ou no para aquém do que o Outro diz, na forma do desejo. Nesse sentido, a alienação retorna sob a forma do desejo, pois o sujeito 
pode se aproximar de sua falta, à custa de um deslizamento no sentido; mas isso parte do reconhecimento do desejo do Outro, de quando o sujeito se depara com a questão crucial acerca do desejo do Outro: "O que o Outro quer de mim?"

Lacan nos dá uma bela imagem da separação: "O sujeito vem jogar sua partida" (Lacan, 1988a, p. 208). Esta não é uma boa metáfora apenas para a separação, modo lógico de pensarmos o sujeito em sua causação, mas, sobretudo, para a transferência. Se pela transferência o sujeito "atualiza" suas relações iniciais com o Outro (Lacan, 1992), é também a partir dela que o sujeito deixa entrever uma falta constitutiva, manifesta em seu desejo.

Neste sentido, Freud nos indica que pelo manejo da transferência se produzirá a centralização do conflito inconsciente na "neurose de transferência", em que a repetição encontrará seu "playground" (Freud, 1915/1980). No texto freudiano em alemão encontramos o termo tummelplatz (1999), que quer dizer campo de jogos, numa clara referência ao brincar e à ação que a transferência oferta à repetição (Freud, 1915/1986). Lembremos que a observação do brincar foi um dos motores para que Freud, em sua obra, postulasse uma repetição que atravessa os limites do sentido e inaugura o registro de um além do princípio do prazer.

A liberdade de expressão que a transferência concede à repetição, para nós, destaca o real da repetição, pelo qual um encontro falho se presentifica entre o sujeito e o analista. O véu da repetição significante indicado, por exemplo, nos motivos inconscientes para a escolha de determinado analista, e não de outro, deixa encoberto este encontro sempre faltoso, essa não realização. À insistência significante, que visa encobrir a impossibilidade do encontro, o analista responde, segundo Freud (1915/1986), com a abstinência, visando destacar o real da impossibilidade do encontro amoroso.

Em Posição do inconsciente Lacan (1988b) nos dá outra imagem do que vem a ser a separação enquanto operação do sujeito junto à sua constituição a partir da linguagem. Ressalta o autor que aí o sujeito promove um ataque à cadeia. $\mathrm{O}$ ataque à cadeia remete diretamente a um jogo próprio do sujeito. Entendemos que por esse movimento de torção da alienação o sujeito vem a se servir da linguagem, utilizando-se dela e não sendo apenas utilizado por ela. Destaca-se aí a produção de um lugar particular do sujeito na cadeia significante. Isso se dá, como nos diz Lacan (1988b), "[porque o sujeito] vem operar com sua própria perda, a qual o reconduz a seu começo"(Lacan, 1988b, p. 858); contudo, jogar sua partida implica em apropriar-se das regras e instrumentos do Outro, e isso só se dá a partir da possibilidade do reconhecimento da dívida simbólica que inicialmente nos constitui.

\section{OS OPERADORES LÓGICOS NO VIVO DE UMA PSICANÁLISE: O CASO MINNA}

Fuentes (2008) discute, na conversação clínica com Jacques Alain Miller, em Barcelona, o caso clínico de Minna, atingida pelos ataques terroristas de março de 2005 em Madri. Imigrante romena, Minna encontrava-se em Madri quando foi surpreendida em um café pelas explosões nos trens e pela multidão apavorada e fugiu sem rumo ante o pavor que experimentou. Nesta fuga encontrou-se com um homem caído no chão, ensanguentado, “(...) como um Cristo estirado" (Fuentes, 2008, p. 18), imagem que não cessa de reaparecer em seus pesadelos. Ela busca ajuda na rede assistencial local, sofrendo de angústia, insônia e pesadelos. Culpa-se por ter fugido e não ter tido condições de auxiliar os feridos, o que teria respondido ao que seu pai gostaria, como membro da Igreja dos Adventistas do Sétimo Dia. Movido pela paixão de Cristo, o pai a ensinara a dar sempre a outra face ante a agressão do semelhante e sua fuga a tinha impedido de estar à altura deste ideal. Este Cristo estirado que cobra sua falta vem perturbá-la com pesadelos. Fuentes (2008) sublinha que o recurso ao ideal paterno não fez frente ao real traumático advindo do episódio, e que Minna precisa responder por outra via. Como resposta à não desculpabilização do analista, a paciente em questão desliza para o ódio dirigido ao outro - no caso, os terroristas. É contrariamente à posição idealizada do pai, que exige uma reposta de amor à agressão, que a analista deduz sua posição, dando espaço ao ódio e possibilitando um desenrolar significante a partir do Cristo ensanguentado e amoroso que insiste em irromper sem mediação possível.

Durante as vinte sessões desta psicanálise os efeitos terapêuticos rápidos logo se apresentaram, na normalização do sono e na suspensão desta imagem invasora do Cristo ensanguentado. Embora o tema dos efeitos terapêuticos rápidos em Psicanálise seja extremamente profícuo e motivador, não o enfatizaremos aqui. $\mathrm{O}$ caso nos interessa, particularmente, para demonstrar a emergência das operações de alienação e da separação no curso dessa análise. A análise sucinta deste caso, que se marca em seis sonhos relatados, auxilia muito nosso intuito. Os extratos transcritos aqui se situam na intenção de 
ilustrar os operadores lógicos da alienação e da separação no vivo de uma psicanálise ${ }^{2}$.

Uma sensação de estranhamento invade a paciente quando novamente os terroristas iniciam suas atividades e ela não se sente mais "em casa" e protegida na Espanha. Como alguns conterrâneos, ela cogita voltar à sua terra natal, onde deixou seu filho. Uma série de sonhos confirma a transferência e produz um basta à angústia, e, como diz a autora “(...) produz a restituição da trama do sentido e a inscrição do trauma na particularidade inconsciente do sujeito" (Fuentes, 2008, p. 21). Discutir um pouco estes sonhos pode nos fazer identificar melhor o "ataque à cadeia" de que nos fala Lacan (1988a) a propósito da separação.

O sonho que mobiliza a demanda de tratamento é a apresentação do trauma manifesto no aparecimento do rosto do Cristo ensanguentado, que cobra sua posição ideal não obedecida. $\mathrm{O}$ desaparecimento deste sonho é o principal efeito terapêutico rápido ilustrativo da conversação em que o caso é discutido.

No segundo sonho o olhar reaparece, agora mediado pela transferência. A paciente é olhada tranquilamente e uma mulher vem falar com ela, convidando-a a ficar consigo e com muitos outros. A suposição de saber se apresenta, demarcando a alienação na entrada em análise. É importante aqui sublinharmos que a alienação dá a partida da cadeia significante. É a partir de um significante advindo do campo do Outro que o sujeito pode interrogar-se acerca de sua determinação.

No terceiro sonho, o sujeito “(...) encontra uma saída e sai” (Fuentes, 2008, p. 21). A paciente encontra-se nos subterrâneos da capital da Romênia, onde desvalidos se drogam. Uma cigana está atrás dela. Ela vê uma luz e se dirige para a saída confirmação da transferência que se manifesta claramente na superação de uma condição alienante, já que as associações que advêm a partir do sonho dão conta de uma oposição aos ditos de sua mãe. Segundo esta última, ciganas não dão boa sorte.

Outro ponto demonstrativo da alienação, que se manifesta já em sua vacilação, é que, ao mesmo tempo em que dá conta de analisar este sonho a partir de sua relação com o Outro, a paciente declara ter sentido,

2 No artigo, intitulado "Trauma e sintoma: da generalização à singularidade" Besset, V. L., Brito, B. P. M., Costa, L. S., Desiderio, A., Dupim, G. V., Genial, L., Zanotti, S. V. \& Vieira, M. P. (2006) discutem outro aspecto do mesmo caso clínico. No referido artigo as autoras discutem a questão do trauma em sua abordagem pela psicanálise, enfatizando a importância da responsabilização do sujeito na direção do tratamento do traumático. pela primeira vez, raiva de seus pais, por estes se haverem recusado a ajudar o neto, seu filho, na resolução de um problema mecânico no carro porque era sábado, dia em que a religião destes proíbe o trabalho. Podemos encontrar aqui referências clínicas à abertura para a separação, a partir do reconhecimento da falta do Outro.

Um novo sonho advém, chamado pela autora de "O fio da vida", após quatro meses de trabalho: "Sonhei com um parafuso, eu dava voltas com um fio ao redor do parafuso, fazia e desfazia. Mais fazia que desfazia" (Fuentes, 2008, p. 22). A homofonia em romeno entre as palavras parafuso e serpente é ressaltada pela própria sonhadora, e ela indaga à analista se em espanhol existe uma expressão semelhante ao "fio da vida" que existe em romeno. A clara referência ao trabalho de construção do tecido significante contido no fazer e desfazer é o ponto fundamental de nossa ilustração do trabalho da alienação e da separação na análise.

$\mathrm{O}$ quinto sonho introduz a vertente fálica no trabalho de análise, segundo a autora. A paciente sonha com um crocodilo que ataca a todos, mas que não a amedronta. Ela o domina, sustentando-o de cabeça para baixo. No sexto sonho, que ocorre perto do fim do tratamento de seis meses - tempo estabelecido para o tratamento, segundo a instituição em que ocorre -, a paciente relata que sonhou com uma mulher bastante conhecida que acaba de falecer, aparentemente por suicídio. Este sonho remete, para a autora, à própria posição da paciente, que se ofertava ao sacrifício. Note-se que neste período a paciente relata ter-se decidido a procurar tratamento para um quisto no útero, do qual já sabia desde muitos meses, antes do advento dos ataques terroristas. A autora acrescenta esta resolução aos efeitos terapêuticos rápidos do início do tratamento. Este sonho remete, para a autora, à posição inicial da paciente, e neste sentido, à possibilidade emergente da morte que se apresenta. Ainda para a autora, “(...) a emergência do primeiro real é a oportunidade para poder tratar o segundo real" (Fuentes, 2008, p. 24).

Neste sentido, a experiência traumática pode, pela análise, dar partida a uma separação, que se mostra mais eficazmente na separação que ela traça em relação aos desvalidos da Romênia, nos subterrâneos de Bucareste. A separação da determinação do ideal paterno se dá pelo reconhecimento de seu ódio e de sua vontade de ficar e construir em terra estrangeira. Mais além da imigração, a paciente pode envolver-se num fazer que a distancia das determinações alienantes do Outro. 
No último sonho relatado pela autora, a paciente relata que “(...) acordava e aos pés da cama havia um homem sem rosto. A sensação que sentia era de tranquilidade" (Fuentes, 2008, p. 22). O olhar mantém-se presente, mas a posição do sujeito se modificou consideravelmente a partir de uma impossibilidade traumática até esta tranquilidade diante de um homem sem rosto. Para a autora, a ausência do rosto remete à ausência da morte e da recriminação.

Vemos que o sujeito parte da identificação alienante aos significantes advindos do campo do Outro; porém, como já frisamos, sua definição a partir do significante promove uma vacilação em seu ser, já que parte do Outro sua designação, na montagem de sua fantasia. Do desvanecimento oriundo dessa identificação, pela oferta da analista, o sujeito parte em direção ao incessante questionamento sobre seu ser, não sem se perguntar sobre o desejo do Outro.

\section{REFERÊNCIAS}

Besset, V. L, Brito, B. P. M., Costa, L. S., Desiderio, A., Dupim, G. V., Genial, L., Zanotti, S. V., \& Vieira, M. P. (2006). Trauma e sintoma: da generalização à singularidade. Revista Mal Estar e Subjetividade, 2, 311-331.

Brodsky, G. (2008). Hic et nunc. Revista Opção Lacaniana, 52, 182185.

Brousse, M. (2008) A origem e o lugar dos objetos. In Brousse, M. Arquivos da Biblioteca: Conferências de Marie-Hélène Brousse (pp. 13-29). Rio de Janeiro: Escola Brasileira de Psicanálise.

Descartes, R. (1996) Meditações. Os Pensadores. São Paulo: Ed. Abril Cultural.

Doumit, E (1996). Alienação. In Kaufmann, P. (Ed.), Dicionário enciclopédico de Psicanálise. O legado de Freud e Lacan. (pp. 2025). Rio de Janeiro: Jorge Zahar.

Freud, S. (1980). Recordar, repetir e elaborar. In Obras completas. Edição Standard Brasileira das Obras Psicológicas Completas de Sigmund Freud (pp. 191-206) Rio de Janeiro: Imago (Texto original publicado em 1915).
Freud, S. (1986). El malestar en la cultura. In Obras completas de Sigmund Freud (pp. 27-62) Buenos Aires, Argentina: Amorrortu. (Texto original publicado em 1930).

Freud, S. (1999). Gesammelte Werke. Fischer: Frankfurt am Main.

Freud, S. (2006). O inconsciente. In Escritos sobre a Psicologia do Inconsciente. Obras Completas de Sigmund Freud (pp. 13-74). Rio de Janeiro: Imago (Texto original publicado em 1915).

Fuentes, A. (2008). Minna: O fio da vida. In Miller, J. Efeitos terapêuticos rápidos em Psicanálise. Belo Horizonte: Escola Brasileira de Psicanálise - Scriptum Livros.

Harari, R. (1990). Uma introdução aos quatro conceitos fundamentais de Lacan. Campinas, SP: Papirus.

Lacan, J. (1988a). O seminário. Livro 11. In Os quatro conceitos da psicanálise. Rio de Janeiro: Jorge Zahar.

Lacan, J. (1988b). Posição do inconsciente. In Escritos (pp. 843-864). Rio de Janeiro: Jorge Zahar.

Lacan, J. (1992). O seminário. Livro 8. A transferência. Rio de Janeiro: Jorge Zahar.

Lacan, J. (2008). O seminário, livro 16 de um Outro ao outro. Rio de Janeiro: Jorge Zahar.

Laurent, E. (1997). Alienação e separação I. In Feldstein, R., Fink, B., Jaanus, M. (Orgs.), Para ler o seminário 11 de Lacan (pp. 31-41). Rio de Janeiro: Jorge Zahar.

Miller, J. A. (2010). Extimidad. Buenos Aires: Paidós.

Milner, J. C. (2010). Linguística e Psicanálise. Estudos Lacanianos, 2 (4), 177-191.

Nascimento, M. B. (2010). Alienação, separação e a travessia do fantasma. Estudos Lacanianos, 2 (4), 283-294.

Soler, C. (1997). O sujeito e o Outro I. In Felstein, R., Fink, B., Jaanus, M. (Orgs.), Para ler o seminário 11 de Lacan (pp. 52-57). Rio de Janeiro: Jorge Zahar.

Endereço para correspondência: $\quad$ Maria Angélica Mello Pisetta. Rua São Sebastião, 525 bloco 9B, Apt. 201, Bairro São Sebastião, CEP 25645-045, Petrópolis-RJ, Brasil. E-mail: angelica.pisseta@ucp.br. 